\title{
STUDY OF THE EFFECT OF MOISTURE CONTENT AND BENDING RATE ON THE FRACTURE TOUGHNESS OF ROCKS
}

\author{
Leona VAVRO * and Kamil SOUČEK
}

\author{
Institute of Geonics AS CR, v. v. i., Studentská 1768, 70800 Ostrava-Poruba, Czech Republic \\ *Corresponding author's e-mail: leona.vavro@ugn.cas.cz
}

(Received September 2012, accepted May 2013)

\begin{abstract}
Generally, rock material failure is controlled by cracks under specific conditions. The study of rock fracture toughness belongs to the current frequent directions of research in the area of rock failure. The present paper describes the effects of parameters influencing the resultant properties of rock materials (bending rate, rock moisture) during fracture toughness measurement of different kinds of rocks (sandstone, marble, granite). The highest fracture toughness values were found in the marble samples. This is probably due to the inner structure of analysed marble, which is composed of only one mineral (calcite) and also has a lower porosity than the used granite. The lowest fracture toughness values were found in the sandstone sample, and reached c. 17-30\% of the measured fracture toughness values of the analysed granite and marble samples. As in the case of the other mechanical properties of rocks (e.g. uniaxial compressive strength) also in the case of higher sandstone (carboniferous) moisture the fracture toughness values decrease and its deformation ability increases.

Preparation of samples for fracture toughness tests and performance of these tests are more complicated than in the case of tensile tests (e.g. the Brazilian test) and therefore this contribution presents a comparison between fracture toughness of analysed rocks and tensile strength values. The measured data in this study considering the fracture toughness tests and Brazilian tests were compared with results published by Zhang (2002).
\end{abstract}

KEYWORDS: fracture toughness, bending rate, tensile strength

\section{INTRODUCTION}

Each rock is characterized by specific mechanical, temperature, and chemical properties which developed during its genesis millions of years ago. From a mechanical point of view the study of failure and determination of failure criteria of rocks in connection with the type of loading on the rocks represent one of the basic rock engineering problems. Very often the phenomenological theories of rock fracture are used. These theories quantify the spatial orientation of the failure plane in relation to the stress state in the rocks. Ones are for example a criterion of maximum shear stress, the Coulomb failure criterion, and the generalized Mohr criterion (Zang and Stephansson, 2010). On the other hand the mechanistic fracture theories assume that incipient cracks exist in the rock, which by nature represent a concentrator of the local stress. These cracks control the rock material failure under specific conditions. Fracture mechanics deals with the study of fracture toughness, which is a material attribute. The study of rock fracture toughness is one of the current frequent directions of research in the area of rock failure. The present paper describes the effects of parameters influencing the resultant properties of rock materials (bending rate, rock moisture) in fracture toughness measurements of different kinds of rocks. This contribution deals with the empirical correlation of fracture toughness and tensile strength too.

\section{FRACTURE TOUGHNESS}

Ordinary rock material contains cracks (in fact, there are also pores, impurities, dislocations, etc.). There is a high stress concentration, which occurs on the tips of these cracks during their loading. The occurrence of small cracks greatly decreases the rock material resistance to external loading (cracks can propagate uncontrollably).

According to Griffith's theory, unstable crack propagation occurs when the stress intensity factor (K) reaches a constant critical value. This value is called the fracture toughness of rocks $\left(\mathrm{K}_{\mathrm{c}}\right)$. The parameter $\mathrm{K}$ which reflects the stress intensity factor at the crack tip. The lower indexes at the parameter $\mathrm{K}$ distinguish three basic modes of loading for a crack (Fig. 1).

\section{SELECTION OF MATERIALS AND PREPARATION OF TEST SPECIMENS}

For the experiments, the rocks were selected to represent all three petrographic types of rocks: igneous, sedimentary, and metamorphic. Particular 

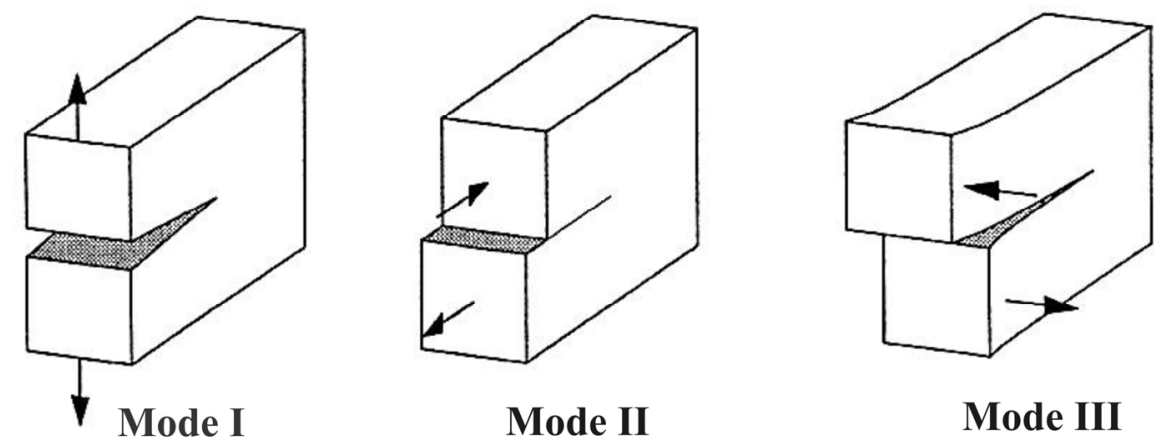

Mode III

Fig. 1 Three basic modes of loading for a crack (opening mode, sliding mode, tearing mode).

rock samples were removed from quarries and specimens of cylindrical shape were prepared. Fracture toughness measurements were carried out on four rocks types:

- $\quad$ Fine-grained granite from the site of Černá Voda. The rock is composed of quartz, potassium feldspar, plagioclase, and biotite and its structure is evenly grainy.

- Coarse-grained marble from the site of Horní Lipová. This is a monomineral rock composed of calcite, with occasional phlogopite flakes. The structure is parallel.

- Fine-grained sandstone from the Javorka site. The average grain size is $0.14 \mathrm{~mm}$. The sandstone is composed dominantly of sub-angular to semioval monomineral quartz grains, with less frequent grains of quartzite, granitic rocks, and kaolinite potassium feldspars. Clastic muscovite flakes are very rare. The matrix of sandstone is clayey (with a predominance of kaolinite) and sometimes very weakly quartzite. Secondarily, the pore space and matrix are saturated with hydrated oxides of Fe and $\mathrm{Mn}$.

- Fine-grained carboniferous sandstone from the Paskov site. The average grain size $\left(M_{D}\right)$ is $0.17 \mathrm{~mm}$. The sandstone is composed of angular and sub-angular quartz grains, and there are also grains of biotite, muscovite, siderite, and potassium feldspar. The matrix is decomposed clayey sandstone, with some quartzite.

To measure the fracture toughness, test specimens in the form of a drill core with a diameter of $49 \mathrm{~mm}$ and a length of about $190 \mathrm{~mm}$ were prepared. The incision profile with the internal angle of $90^{\circ}$ is positioned perpendicular to the axis of the core body (see Fig. 2). The incision width is $2 \mathrm{~mm}$. In addition, comparative measurements were performed for the other above-mentioned types of rocks at a comparable bending rate and different bending rates. The same types of rocks were also examined by Brazilian tests. The cylindrical specimens were prepared from drill cores with a diameter of $49 \mathrm{~mm}$ and length of $25 \mathrm{~mm}$.

The water contained in rock significantly influences its behaviour. Therefore, we studied the effect of moisture on the fracture parameters of the selected rock material (Lesňák, 1975). Water absorption is defined as the ratio of the weight of water received by stone under specified physical conditions to the weight of dry stone. It is expressed as a percentage by weight (ECS, 2001). The water absorption of the selected materials was determined according to standard laboratory tests and ranged between 0.41 and $6.50 \%$ by weight (see Table 1 ).

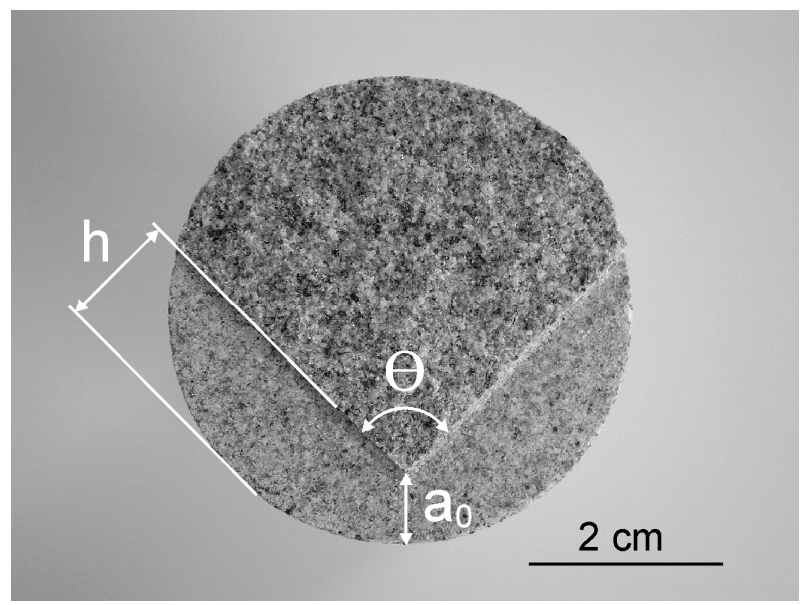

Fig. 2 The geometry of the chevron bend specimen $\left(a_{o}\right.$ is the chevron tip distance from the specimen surface and is equal to $0.15 \mathrm{D}$, $\theta=90^{\circ}, \mathrm{h}$ is the depth of the cut in the notch flank). 
Table 1 Density and water absorption of selected rocks.

\begin{tabular}{llcc}
\hline Rock & Locality & $\begin{array}{c}\text { Bulk density } \\
{\left[\mathrm{kg} \cdot \mathrm{m}^{-3}\right]}\end{array}$ & $\begin{array}{c}\text { Water absorption } \\
{[\% \text { by weight] }}\end{array}$ \\
\hline Granite & Černá Voda & 2607 & 0.41 \\
Marble & Horní Lipová & 2703 & 0.14 \\
Sandstone & Javorka & 1993 & 6.50 \\
Sandstone & Paskov & 2550 & 1.70 \\
(carboniferous) & & & \\
\hline
\end{tabular}

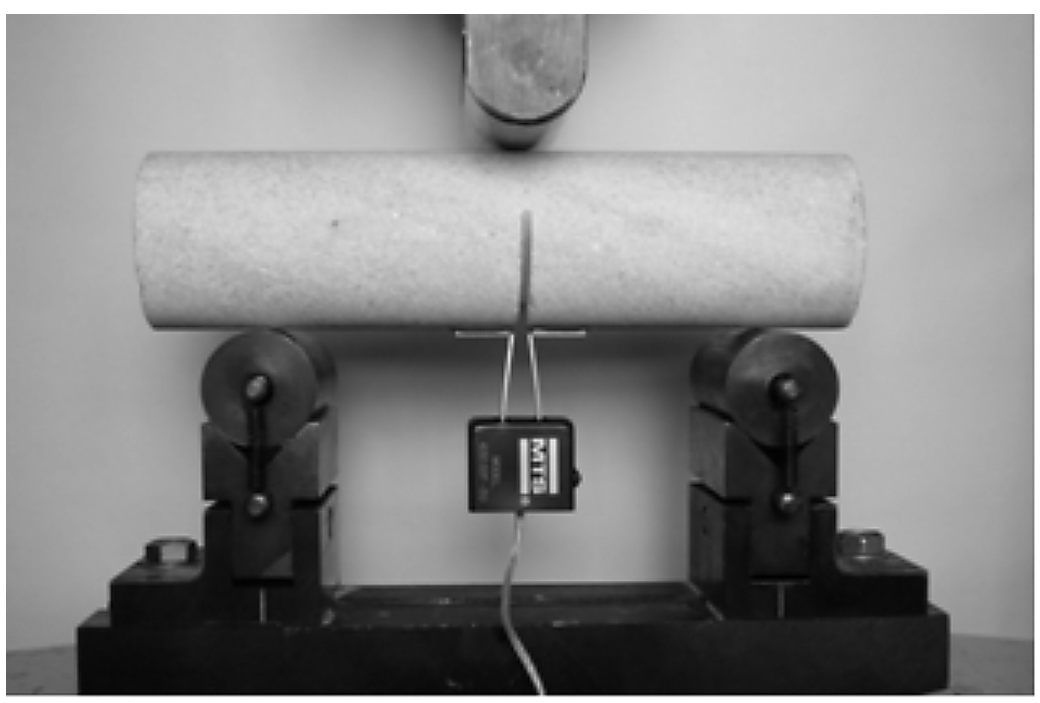

Fig. 3 Test equipment with the extensometer.

\section{TESTING PROCEDURE}

The tests were carried out at room temperature on an FPZ 100 power press with displacement control. The measurement of rock fracture toughness was performed using a three-point bending test on the selected rocks using a specimen type CB (Chevron Bend) with the Mode I method of loading (Figure 1). Figure 3 shows the test set-up with a cylindrical specimen and clip-on-cage-type extensometer. With the extensometer it is possible to measure the crack face opening (COD - crack opening displacement). The fracture toughness of mode $\mathrm{I} \mathrm{K}_{\mathrm{IC}}$ is represented by the following equation (Ouchterlony, 1986).

$$
K_{I C}=\frac{Y \cdot P_{\max }}{D^{1.5}}
$$

$\mathrm{Y}$ is independent of material property and is a function of $\mathrm{a}_{0}$ only (Figure 2 ) and:

$$
Y=\left[1.835+\frac{7.15 a_{0}}{D}+9.85\left(\frac{a_{0}}{D}\right)^{2}\right] \frac{S}{D}
$$

\section{EXPERIMENTAL RESULTS}

On the basis of the resultant fracture toughness values of the analysed rocks we can state that:

- The highest fracture toughness values were found in the marble samples (Table 2). This is probably due to the inner structure of analysed marble, which is composed of only one mineral (calcite) and also has a lower porosity than the used granite. Also, the granite structure is more complicated than that of the analysed marble. The analysed sandstone had the lowest fracture toughness values, which were influenced by its high porosity in comparison with marble and granite and by the mechanical properties of sandstone cement.

- The lowest fracture toughness values were found in the sandstone sample, and reached c. 17-30\% of the measured fracture toughness values of the analysed granite and marble samples (see Table 3 and Fig. 4).

- The higher fracture toughness values of the Horní Lipová marble samples were recorded at lower loading displacement rates, which were probably 
Table 2 Fracture toughness and tensile strength values of the selected rocks.

\begin{tabular}{|c|c|c|c|c|}
\hline Rock & $\begin{array}{c}\text { Fracture toughness } \\
{\left[\mathrm{MPam}^{1 / 2}\right]}\end{array}$ & $\begin{array}{l}\text { Bending rate } \\
{\left[\mathrm{mm} \cdot \mathrm{min}^{-1}\right]}\end{array}$ & $\begin{array}{c}\text { Tensile strength } \\
{[\mathrm{MPa}]}\end{array}$ & $\begin{array}{l}\text { Bending rate } \\
{\left[\mathrm{mm} \cdot \mathrm{min}^{-1}\right]}\end{array}$ \\
\hline \multirow{4}{*}{ Granite } & 1.29 & 0.1 & 6.74 & 0.1 \\
\hline & 1.43 & 0.1 & 7.48 & 0.1 \\
\hline & 1.31 & 0.1 & 7.06 & 0.1 \\
\hline & 1.39 & 0.1 & 7.28 & 0.1 \\
\hline \multirow{4}{*}{ Marble } & 1.83 & 0.1 & 7.55 & 0.1 \\
\hline & 1.79 & 0.1 & 4.89 & 0.1 \\
\hline & 1.82 & 0.1 & 5.63 & 0.1 \\
\hline & 1.71 & 0.1 & 4.60 & 0.1 \\
\hline \multirow{4}{*}{$\begin{array}{l}\text { Javorka } \\
\text { sandstone }\end{array}$} & 0.37 & 0.1 & 2.48 & 0.1 \\
\hline & 0.42 & 0.1 & 2.48 & 0.1 \\
\hline & 0.34 & 0.1 & 2.44 & 0.1 \\
\hline & 0.51 & 0.1 & 2.90 & 0.1 \\
\hline
\end{tabular}

Table 3 Ratio of fracture toughness values of Javorka sandstone to granite and marble values.

\begin{tabular}{llll}
\hline & \multicolumn{3}{c}{ Bending rate $\left[\mathrm{mm} \cdot \mathrm{min}^{-1}\right]$} \\
\hline & 0.01 & 0.1 & 1 \\
Javorka sandstone /Granite [\%] & 0.26 & 0.20 & 0.31 \\
Javorka sandstone/Marble [\%] & 0.17 & 0.20 & 0.28 \\
\hline
\end{tabular}

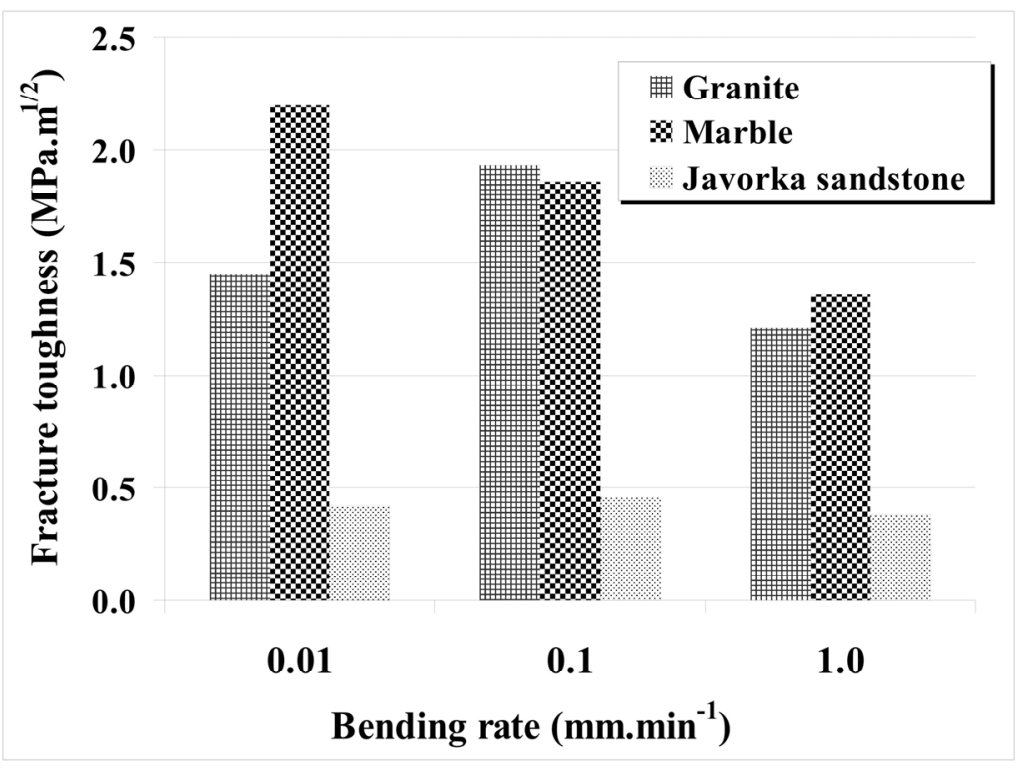

Fig. 4 Fracture toughness values of the analysed rock.

related to the rheological properties of rocks and amount of elastic deformation energy realized on the test system per time unit. In case of loading displacement rates 0.1 and $1.0 \mathrm{~mm} \cdot \mathrm{min}^{-1}$, this dependency was observed only at granite and Javorka sandstone samples. This fact may be caused by different mineralogical composition and structure, and texture properties of these two rocks - compared to the measured marble. This kind of marble is more suitable for this analysis because it is composed of only one mineral and his texture seems to be more homogeneous.

- From the graph in Figure 5 it is clear that the COD values found in the granite and marble are much lower (they reach up to $0.04 \mathrm{~mm}$ at the most) than those of the sandstone samples (the Javorka sandstone values range from 0.05 to $0.09 \mathrm{~mm}$ ). These values reflect the more brittle behaviour of granite and marble samples. 


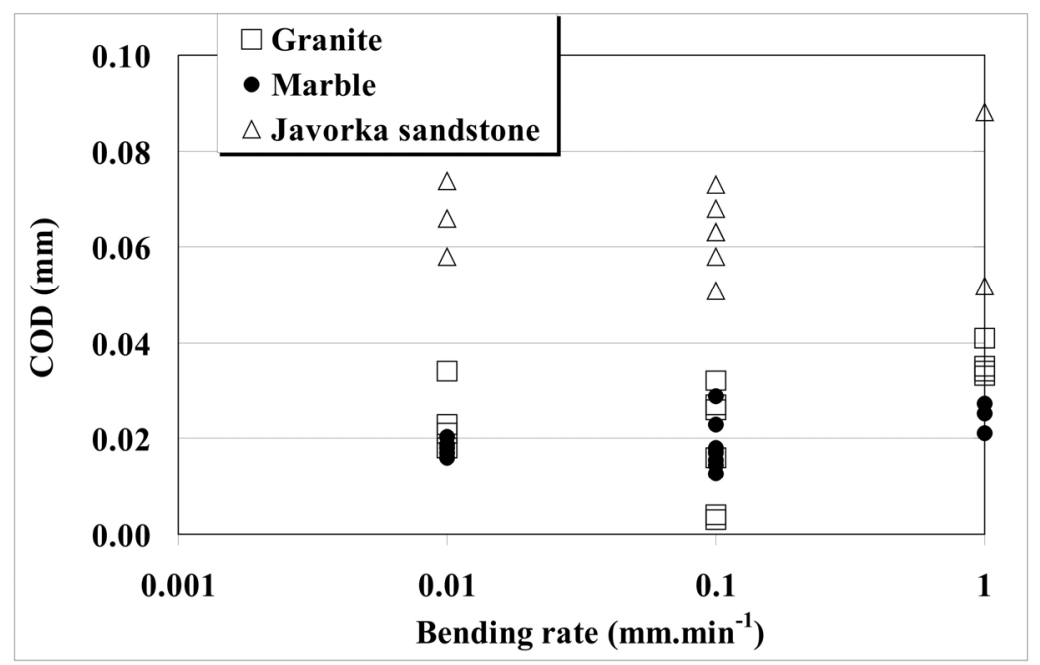

Fig. 5 COD (crack opening displacement) vs bending rate.

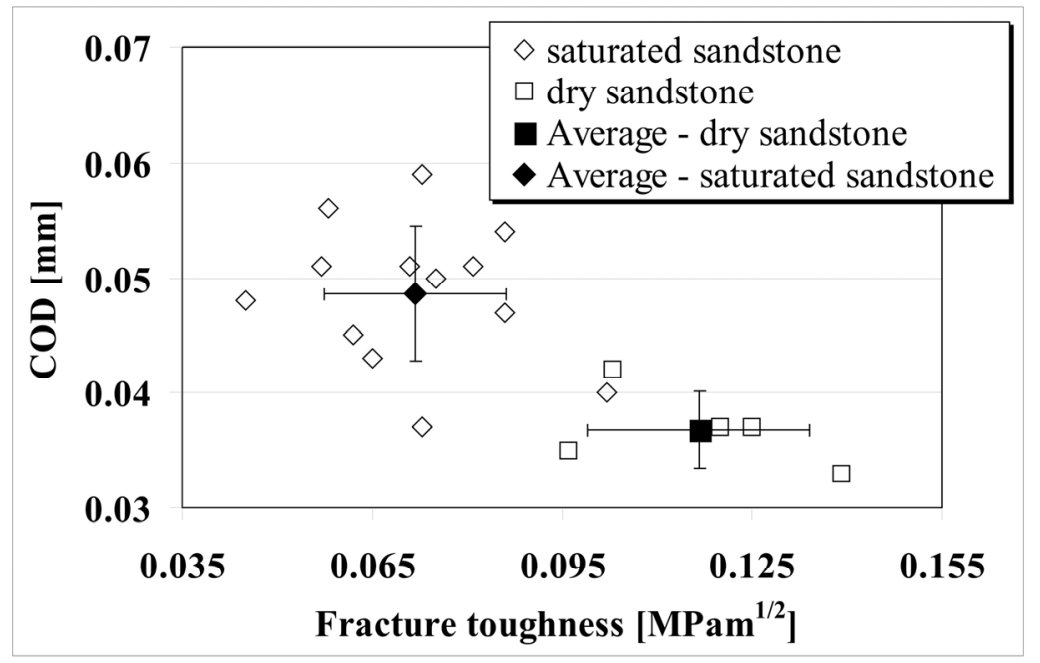

Fig. 6 Fracture toughness of dry and saturated Paskov sandstone (tested at a bending rate of $0.1 \mathrm{~mm} \cdot \mathrm{min}^{-1}$ ).

- As in the case of other mechanical properties of rocks (e.g. uniaxial compressive strength), the fracture toughness decreases (while the deformation ability increases) with an increase in moisture content of the rock material (see Figure 6). The average moisture content of the saturated Paskov sandstone was $1.7 \%$.

\section{FRACTURE TOUGHNESS VERSUS TENSILE STRENGTH}

Preparation of the samples for the fracture toughness test and performance of the test are more complicated than in the case of, for example, the tensile tests (the Brazilian test, for example, is a very simple test and is probably the most widely used kind of tensile test). According to the literature (Zhang, 2002), the fracture toughness values can be related to the tensile strength values of the different rocks. There are some main similarities in the fracture patterns occurring in the tensile strength and fracture toughness tests, as follows (Zhang, 2002):

- The specimens in both tests usually form only two fractured surfaces under static (quasi-static) or low-speed impact loading, which indicates that the failure of each specimen is due to the extension of a single crack (or the coalescence of a few micro-cracks in the same plane). From this point the formation of the fractured surface of a tensile strength specimen is similar to that of a fracture toughness specimen.

- The meso-fracture characteristics of the fractured surfaces of the specimens in both tests are similar to each other, that is, on both kinds of fractured surfaces there are micro- and meso-cracks 


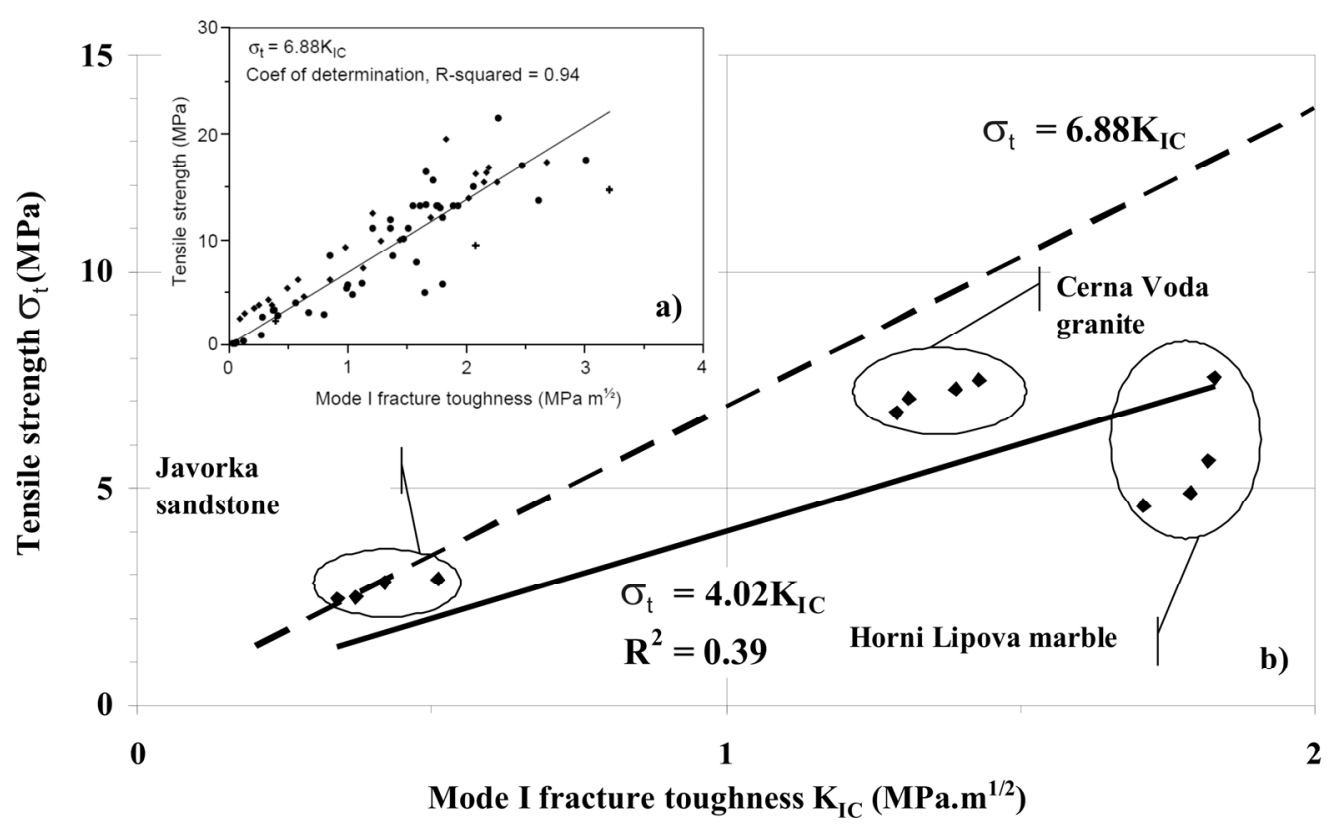

Fig. 7 Relation between fracture toughness and tensile strength of rocks:

a) data published by Zhang (2002), b) data obtained from the present study.

induced by loading. In addition, on most fractured surfaces of dynamically broken strength and fracture specimens there are some clear branching macro-cracks.

Z. X. Zhang (2002) states "According to previous studies (Whittaker et al., 1992) there are three basic fracture criteria: maximum principal stress maximum energy release rate and minimum strain energy density. However Whittaker et al. argued that experimental results available showed that for rocks fracture toughness is controlled by the maximum principal stress (i.e. tensile strength) instead of strain energy (Huang and Wang, 1985). This implies that there is an inherent relation between fracture toughness and tensile strength".

According to Zhang (2002), the relation between Mode I fracture toughness $\left(\mathrm{K}_{\mathrm{IC}}\right)$ and tensile strength $\left(\sigma_{t}\right)$ of different rocks can be empirically expressed by the linear regression $\sigma_{\mathrm{t}}=6.88 \mathrm{~K}_{\mathrm{IC}}$ (see Fig. 6a). The fracture toughness and tensile strength values of the analysed rocks can be seen in Figure 6b (Zhang, 2002). Our measured experimental data can be fitted by the linear regression $\sigma_{\mathrm{t}}=4.02 \mathrm{~K}_{\mathrm{IC}}$ with a comparatively low coefficient of determination $\mathrm{R}^{2}=0.4$. From Fig. $6 \mathrm{~b}$ it is clear that marble fracture toughness values are considerably lower than the comparable experimental data represented in Fig. 6a. We can see that sandstone and granite fracture toughness values correspond better to the measured experimental data presented in Fig. 6a. If we consider only sandstone and granite fracture toughness values, the linear regression will be closer to the published equation by Zhang (2002), that is, $\sigma \mathrm{t}=5.37 \mathrm{~K}_{\mathrm{IC}}$ with the coefficient of determination $\mathrm{R}^{2}=0.97$. The reason for the considerably lower marble fracture toughness values is probably the inner structure of the used marble. For the purpose of the presented correlation between fracture toughness and tensile strength it will be useful to apply some non-destructive methods for studying the inner structure and visualizing the used rocks before carrying out the fracture toughness tests.

\section{CONCLUSION}

From our point of view and recent experiences obtained from the results of fracture toughness testing, we conclude that it would be useful to implement more detailed investigations in the future, for example:

- Non-destructive methods, namely X-ray computed tomography, should be applied to study the inner structure and to visualize the rocks used before and after fracture toughness testing.

- In the field of the correlation study between fracture toughness and tensile strength it would be advantageous to use direct tensile strength testing (uniaxial tensile testing), which is more sensitive to the inner structure of rocks. On the other hand, direct tensile testing is much more complicated (there are some difficulties in the process of shaping the rock specimens, it is more expensive, etc.) than Brazilian testing. The correlation should be determined for groups of similar rocks (e.g. sedimentary rocks with comparable grain size and comparable cement, metamorphic rocks with comparable structure, foliation, etc.). 
- In the field of the displacement rate effect investigation, higher differences in the magnitude of the displacement rate order should be implemented to give a better understanding of this behaviour, because we found that fracture toughness values do not show well-marked differences at the displacement rates used (1.0, 0.1 , and $0.01 \mathrm{~mm} \cdot \mathrm{min}^{-1}$ ).

- Likewise in the study of the effect of moisture on the fracture toughness values it is necessary to use a different scale of rock moisture.

The empirical study of the correlation between fracture toughness and tensile strength can be very useful because performing fracture toughness tests and preparing the chevron bend specimens is much more complicated than tensile rock testing, especially the Brazilian test. To obtain better results for this correlation it is necessary to realize a much larger number of fracture toughness and tensile tests for different kinds of rocks.

\section{ACKNOWLEDGEMENTS}

This work has been carried out in connection with the project Institute of Clean Technologies for Mining and Utilization of Raw Materials for Energy Use, Reg. No. CZ.1.05/2.1.00/03.0082, supported by the Research and Development for Innovations Operational Programme financed by Structural Funds of the European Union and from the state budget of the Czech Republic. This work was supported by the project SPOMECH (Creating a Multidisciplinary R\&D Team for Reliable Solution of Mechanical Problems, Reg. No. CZ.1.07/2.3.00/20.0070, within the Operational Program "Education for Competitiveness" funded by Structural Funds of the European Union and the state budget of the Czech Republic.

\section{REFERENCES}

Huang, J.A. and Wang, S.J.: 1985, An experimental investigation concerning the comprehensive fracture toughness of some brittle rocks. Int. J. Rock Mech. Min. Sci. Geomech. Abstr., 22, 99-104.

International Society for Rock Mechanics Commission on Testing Methods: 1988, Suggested Methods for Determining the Fracture Toughness of Rock, Int. J. Rock Mech. Min. Sci. Geomech. Abstr., 25(2), 71-96.

Lesňák, O.: 1975, Influence of moisture on physical and mechanical properties of rock in the Ostrava Karviná Coal Field. VVU Ostrava - Radvanice, 121, (in Czech).

Ouchterlony, F.: 1986, A core bend specimen with Chevron Notch for fracture toughness measurements, Rock Mechanics: Key to Energy Production, Proc. $27^{\text {th }}$ U. symp. on Rock Mech., H. L. Hartman, (ED), SME, Littleton Co., 177-184.

Vavro, M., Vavro, L. and Martinec, M.: 2009, Color and structural interesting Cretaceous sandstones of the Czech Republic. Zpravodaj WTA CZ, 1-2, 12-16, (in Czech).

Whittaker, B.N., Singh, R.N. and Sun, G.: 1992, Rock fracture mechanics. Elsevier Science Publisher B.V., Amsterdam, 569 pp.

Zang, A. and Stephansson, O.: 2010, Stress field of the Earth's crust. Springer Science + Business Media B.V., London, 327 pp.

Zhang, Z.X.: 2002, An empirical relation between mode I fracture toughness and the tensile strength of rock. Int. J. Rock Mech. Min. Sci., 39, 401-406. DOI: $10.1016 / \mathrm{S} 1365-1609(02) 00032-1$

European Committee for Standardization (ECS): 2001, Determination of Water Absorption at Atmospheric Pressure - Natural Stone Test Methods, European Standard, 9, (in Czech). 